\title{
Early intraocular pressure response following laser trabeculoplasty
}

\author{
J FRUCHT, S BISHARA, AND U TICHO \\ From the Department of Ophthalmology, Hadassah University Hospital, Jerusalem, Israel
}

SUMmARY The early response in the intraocular pressure following laser trabeculoplasty was investigated in 38 patients. An increase in pressure was found in 16 patients $(42 \%)$, of whom eight had a moderate $(<9 \mathrm{mmHg})$ and eight a severe $(>10 \mathrm{~mm} \mathrm{Hg})$ increase. The maximum increase was recorded during the first post-laser hour in 13 patients $(34.2 \%)$ and at $4 \mathrm{~h}$ in three patients postoperatively. A routine follow-up observation at $4 \mathrm{~h}$ after laser treatment is recommended to prevent 'silent' hypertensive risk.

Laser trabeculoplasty (LTP) has become a major tool for the treatment of open-angle glaucoma. A high rate of success has been reported by most investigators, ${ }^{1.3}$ with only minor complications. A raised intraocular pressure (IOP) during the first three weeks following surgery has been reported to be the most serious complication and may lead to further field loss. ${ }^{2+5}$ The increase in IOP is unpredictable and its prognosis for the individual eye or the success rate of the treatment is not clear. ${ }^{25}$ We studied the changes in IOP during the first 24 hours following laser treatment in order to establish an immediate follow-up regimen after LTP.

\section{Material and methods}

Thirty-eight patients with uncontrolled open-angle glaucoma, 22 males and 16 females, aged 58 to 81 (mean age 62) were included in the study. All the patients were under antiglaucomatous medical treatment, and the visual fields were abnormal in every case. Laser trabeculoplasty was applied to each patient on one eye by means of the Coherent Radiation Argon Laser Unit A900. Eighty to 100 spots were applied at the pigmented trabecular meshwork throughout $360^{\circ}$ of the angle circumference. The IOPs were measured before treatment and $1 / 2$ hour, 1 hour, 4 hours, and 24 hours after LTP. Postoperatively all patients carried on their initial antiglaucomatous medications with additional dexamethasone three times a day. Patients with

Correspondence to Dr J Frucht, Department of Ophthalmology Hadassah University Hospital, PO Box 12000, il-91 120 Jerusalem, Isracl. severe glaucomatous damage in which the IOP increased over $10 \mathrm{mmHg}$ from the initial level were treated with glycerol $50 \%$ by mouth or mannitol $20 \%$ intravenously.

\section{Results}

During the first 24 hours following LTP the intraocular pressures increased by $3.15 \mathrm{mmHg}$ mean value in 16 out of the 38 treated patients $(42 \%)$. Five patients $(13 \%)$ had no change in their IOP, and in 17 $(45 \%)$ the IOP was reduced by 3 to $24 \mathrm{mmHg}$. The pressure increase was moderate $(<9 \mathrm{mmHg})$ in eight patients $(21 \%)$ and severe $(>10 \mathrm{mmHg})$ in the remaining eight patients $(21 \%)$ (Table 1$)$. The maximum increase in IOP was observed during the first postoperative hour in 13 out of the 16 patients. In another patient the IOP continued to increase to maximum levels at 4 hours postoperatively, and in the remaining two cases a rise in IOP was first noted at 4 hours after LTP (Table 2). Over all patients the mean of the pressures at 24 hours was significantly reduced as compared with the prelaser levels ( $\mathrm{p}<0.001$ by Student's $t$ test). In two patients $(5.2 \%)$ a moderate $(<9 \mathrm{mmHg})$ increase in IOP was recorded,

Table 1 Early IOP variations in the 38 patients during the first four hours

\begin{tabular}{lrr}
\hline & No. of patients & $\%$ \\
\hline IOP $\leqslant$ pretreated levels & 22 & 58 \\
IOP increase $\leqslant 9 \mathrm{mmHg}$ & 8 & 21 \\
IOP increase $\geqslant 10 \mathrm{mmHg}$ & 8 & 21 \\
Total & 38 & 100 \\
\hline
\end{tabular}


Table 2 Initial and maximum IOP increase in 16 patients during the first four hours after LTP

\begin{tabular}{|c|c|c|c|c|}
\hline \multirow[b]{2}{*}{ Time } & \multicolumn{2}{|c|}{$\begin{array}{l}\text { Initial pressure rise } \\
(\mathrm{mmHg})\end{array}$} & \multicolumn{2}{|c|}{$\begin{array}{l}\text { Maximal pressure rise } \\
(\mathrm{mmHg})\end{array}$} \\
\hline & $\begin{array}{l}\text { No. of } \\
\text { patients }\end{array}$ & $M e a n \pm S D$ & $\begin{array}{l}\text { No. of } \\
\text { patients }\end{array}$ & Mean $\pm S D$ \\
\hline $1 / 2 h$ & 9 & $6 \cdot 0 \pm 3 \cdot 28$ & 4 & $7 \cdot 25 \pm 4 \cdot 7$ \\
\hline $1 \mathrm{~h}$ & 5 & $6 \cdot 4 \pm 2 \cdot 82$ & 9 & $9 \cdot 55 \pm 4 \cdot 1$ \\
\hline $4 \mathrm{~h}$ & 2 & 11 & 3 & $10 \pm 5 \cdot 29$ \\
\hline
\end{tabular}

and in only one patient the pressure during the first 24 hours following LTP could not be controlled by intravenous mannitol, so that surgical intervention was required. Table 3 demonstrates pressure changes in the group with moderate postlaser pressure increase $(<9 \mathrm{mmHg})$. As shown in this table, in six out. of the eight patients the peaks present at the first postoperative hour had dropped by $4 \mathrm{~h}$ and remained as such thereafter. In the other group of eight patients $(23.6 \%)$ who had a severe increase in IOP $(>10 \mathrm{mmHg})$ a single dose of hyperosmotics was required to control the pressure.

Mild anterior uveitis was observed in all the cases. The severity of the inflammatory process did not correlate with the IOP levels.

\section{Discussion}

All investigators have agreed that an acute increase of IOP may lead to further deterioration of visual field in a glaucomatous eye. Therefore it is of high importance to investigate the timing and levels of such pressure elevation which may occur as a 'silently' during the first 24 hours postoperatively and thus prevent the risk. In our series of 38 patients $16(42 \%)$ had an increase in IOP following LTP. This finding is in keeping with those of other studies. ${ }^{1-8}$ Krupin et al. ${ }^{\circ}$ in a similar study reported that more than $50 \%$ of their patients had an increased IOP over prelaser mean values, but in only $14 \%$ was additional medical therapy required. Hoskins et al. ${ }^{4}$ reported an increase in IOP in $34 \%$ of his patients and persistently raised tension over 24 hours in $6 \%$ only. As results reported here show, 13 of the patients $(34 \cdot 2 \%)$ had a maximum increase in IOP already during the first postoperative hour. This is similar to Krupin et al.'s study, ${ }^{\circ}$ which concluded that the IOP should be followed up for 1-2 hours postoperatively and those patients who have a clinically significant increase should be followed up for at least 24 hours.

According to our findings, in agreement with those of Weinreb et al., ${ }^{7}$ if the raised pressure had declined from its peak after that period, a further increase was unlikely. However, attention should be drawn to the
Table 3 Pressure changes in eight patients with moderate increase of $I O P(<9 \mathrm{mmHg})$

\begin{tabular}{lllll}
\hline & Before LTP & $\begin{array}{l}I O P \\
(\mathrm{mmHg}), \\
30-60 \mathrm{~min} \\
\text { after LTP }\end{array}$ & $\begin{array}{l}4 \mathrm{~h} \text { after } \\
L T P\end{array}$ & $\begin{array}{l}24 \mathrm{~h} \text { after } \\
\text { LTP }\end{array}$ \\
& \multicolumn{5}{l}{} & \\
\hline Case 1 & 23 & 32 & 20 & 16 \\
Case 2 & 28 & 32 & 29 & 17 \\
Case 3 & 22 & 30 & 26 & 19 \\
Case 4 & 26 & 30 & 27 & 20 \\
Case 5 & 23 & 30 & 26 & 16 \\
Case 6 & 24 & 27 & 22 & 16 \\
Case 7 & 28 & 32 & 32 & 24 \\
Case 8 & 26 & 30 & 28 & 20 \\
\hline
\end{tabular}

three patients in our series who had a maximum rise in IOP only four hours after LTP. In two of those it was first recorded at $4 \mathrm{~h}$ post laser treatment. Therefore it is suggested that routine follow-up should be extended to four hours postoperatively. Fisrthermore, in another study a routine six hours' follow'up was suggested.' On an outpatient regimen such a long follow-up might be inconvenient, but our findings suggest it should be considered.

Various factors may be associated with the acute increase in IOP. A post-LTP inflammatory response is one of them. Post-LTP iritis was observed in all our patients, but we could not correlate the increase in IOP with the inflammatory response. The inflammation may be mediated by prostaglandins or other endogenous hormones. ${ }^{911}$ It may therefore be reasonable to assume that fewer burns given to the trabecular angle will induce less inflammatory response and will be associated with less IOP elevation. This line of thought was established by Wilensky and Weinreb, ${ }^{3}$ who applied only 25 spots at $90^{\circ}$ of the angle circumference. In their series only 2 out of 21 patients had an IOP increase of over $10 \mathrm{mmHg}$.

In our study the laser spots were targeted at the mid-trabeculum and resulted in pressure increases considerably higher than those in the reports in which the laser was applied to the anterior trabeculum. ${ }^{5 \times 11}$

In summary, we suggest a four-hour regimen of postoperative follow-up. longer evaluation and/or treatment are required if the IOP remains significantly raised.

\section{References}

1 Wise JB. Long term control of adult open angle glaucoma by argon laser treatment. Ophthalmology (Rochester) 1981; 88: 197-202.

2 Thomas JV, Simmons RJ, Belcher CD III. Argon laser trabeculoplasty in the presurgical glaucoma patients. Ophthalmology (Rochester) 1982; 89: 187-92.

3 Wilensky JT, Weinreb RN. Low dose trabeculoplasty. Am J Ophthalmol 1983; 95: 423-6. 
4 Hoskins HD Jr, Hetherington J Jr, Minckler DS, Lieberman MF, Shaffer RN. Complications of laser trabeculoplasty. Ophthalmology (Rochester) 1983; 90: 796-9.

5 Schwartz AL, Kopelman FJ. Four-year experience with argon laser trabecular surgery in uncontrolled open angle glaucoma. Ophthalmology (Rochester) 1983; 90: 771-80.

6 Krupin T, Kolker AE, Kass MA, Becker B. Intraocular pressure the day of argon laser. Trabeculoplasty in primary open-angle glaucoma. Ophthalmology (Rochester) 1984; 91: 361-5.

7 Weinreb RN, Ruderman J, Juster R, Wilenski JT. Influence of the number of laser burns administered on the early results of argon laser trabeculoplasty. Am J Ophthalmol 1983; 95: $287-92$
8 Scwartz LW, Spaeth GL, Traverso C, Greenidge RC. Variations of techniques on the results of argon laser trabeculoplasty. Ophthalmology (Rochester) 1983; 90: 781-4.

9 Unger WG, Cole DF, Bass MS. Prostaglandin and neurogenically mediated ocular response to laser irradiation of the rabbit iris. Exp Eye Res 1977; 25: 209-20.

10 Butler JM, Unger WG, Cole DF. Axon reflex in ocular injury. Sensory mediation of the response of the rabbit eye to laser irradiation of the iris. QJ Exp Physiol 1980; 65: 261-72.

11 Beckman $\mathrm{H}$. Laser trabeculotomy in the treatment of open angle glaucoma. Presented at International Symposium on Laser Surgery for Glaucoma. 20-21 July 1981, Saratoga Springs, New York. 